Paper ID \#19278

\title{
Teaching Engineering Design Through a Wearable Device Design Competi- tion (Evaluation)
}

\section{Dr. Elena Nicolescu Veety, North Carolina State University}

Elena Veety received the Ph.D. degree in electrical engineering from North Carolina State University, Raleigh, NC, in 2011. Her research focused on liquid crystal polarization gratings for tunable optical filters and telecommunications applications. Since 2011, she has been a Teaching Assistant Professor of Electrical and Computer Engineering at North Carolina State University. Currently, she is the Education Director for the NSF Nanosystems Engineering Research Center for Advanced Self-Powered Systems of Integrated Sensors and Technologies (ASSIST).

\section{Prof. Jesse S. Jur, North Carolina State University}

Dr. Jesse Jur is an Assistant Professor of Textile Engineering, Chemistry \& Science at NC State University's College of Textiles, a position he has held since 2011. A graduate of The University of South Carolina, he received his $\mathrm{PhD}$ in Materials Science and Engineering from N.C. State and has spent the last $12+$ years researching primarily at the nanoscale. His research now focuses on applying the use of innovative materials methods to create functional electronic-textiles. Through this research, Dr. Jur is the technology leader for Human Factors and Integration in a National Science Foundation Nano Engineering Research Center for Advanced Self-Powered Systems of Integrated Sensors and Technologies (ASSIST), led by North Carolina State.

Mrs. Hannah Kimrey Elliott,

Mr. James Edward Lamberth III, William G. Enloe Magnet High School

I was born on April 9th, 1983 to Jim and Rose Lamberth in Leasburg, NC. I spent my adolescent years living in Timberlake, NC. I graduated from Person High School in Roxboro, NC in 2001. In 2005 I graduated from North Carolina State University with a B.S. in Science Education and a B.A. in Chemistry. I student taught at Garner Magnet High School in the Fall of 2005. I have been teaching at Enloe Magnet High School in Raleigh, NC since January of 2006 where I have taught earth science, physical science, astronomy, and chemistry. I have been married to Leslie Harris Lamberth of Elizabeth City, NC since August 2014.

In the summer of 2014 I was accepted into the Kenan Fellows Program to work with and learn about Dr. Gail Jones and Dr. Jess Jur's work at the ASSIST (Advanced Self-Powered Systems of Integrated Sensors and Technologies) Center at North Carolina State University as an RET 1 (Research Experience for Teachers.) The ASSIST Center's goal is to create a wearable, self-powered, multi-modal health monitoring device. The following year I was brought back as an RET 2 to work with Hannah Elliott, Dr. Elena Veety, and Dr. Jess Jur to design, market, and implement the Wearable Device Challenge in local middle and high schools. I am currently a part time employee of the ASSIST Center working as an educational outreach liaison to continue the work with the Wearable Device Challenge. 


\section{Teaching Engineering Design Through Wearable Device Design Competition (Evaluation)}

\section{Introduction}

The Wearable Device Challenge (WDC) was developed at the Nanosystems Engineering Research Center for Advanced Self-Powered Systems of Integrated Sensors and Technologies (ASSIST). The Challenge is rooted in the research and innovation ecosystem of the Center and its vision: to have a transformational impact on the way doctors and patients manage wellness through wearable, self-powered health and environmental monitoring systems.

The ASSIST Center ${ }^{1}$ is enabling a paradigm shift in health informatics by creating wearable nanotechnologies that monitor individual health parameters and environmental exposures. Longterm, scientifically accurate sensing enables patients, doctors, and scientists to make direct correlations between health parameters and environmental exposures. This information leads to improved chronic disease prediction, management, and treatment.

As a National Science Foundation funded Engineering Research Center, education and outreach are an integral part of the ASSIS Center's mission and vision. The Wearable Device Challenge described here, aims to disseminate the core of our research to the K-12 community and build the pipeline of young scientists and engineers who will be prepared to continue the important work of identifying and solving the grand global challenges of the future.

\section{Program Description}

At its core, the program teaches middle and high school teachers and students how to apply the Engineering Design Process (EDP) to solve real world problems through a project based approach. The prompt presented to participants is: Design a wearable device for a human, animal, or both, to address a "One Health" related issue. The One Health Initiative ${ }^{2}$ brings light to issues at the intersection of human, animal, and environmental health. This prompt encourages creativity in the brainstorming process to address issues that may be relevant to the participants, their families, or their communities. Within this prompt, we consistently see an amazing range of creative and critical issues that participants choose to address, issues as diverse as the participants themselves: health and safety of farm workers and farm animals, first responder exposure, hydration and UV exposure for athletes, monitoring of specific health conditions like sleep apnea, asthma, seizures, and many more.

The program is structured as shown in Fig.1 below. First, teachers receive training in the form of a 5-week immersive research experience within the Center. Teacher training is also available in the form of a 1 or 2-day workshop hosted by the Center. As part of this training, teachers complete a version of the WDC to familiarize themselves with the process their students will be completing. In conjunction with completing the challenge, teachers also develop lesson plans based around concepts of the challenge that align with their curriculum. Teachers implement the WDC in their schools, and the top teams have an opportunity to present their prototypes at the Center's an annual competition. 


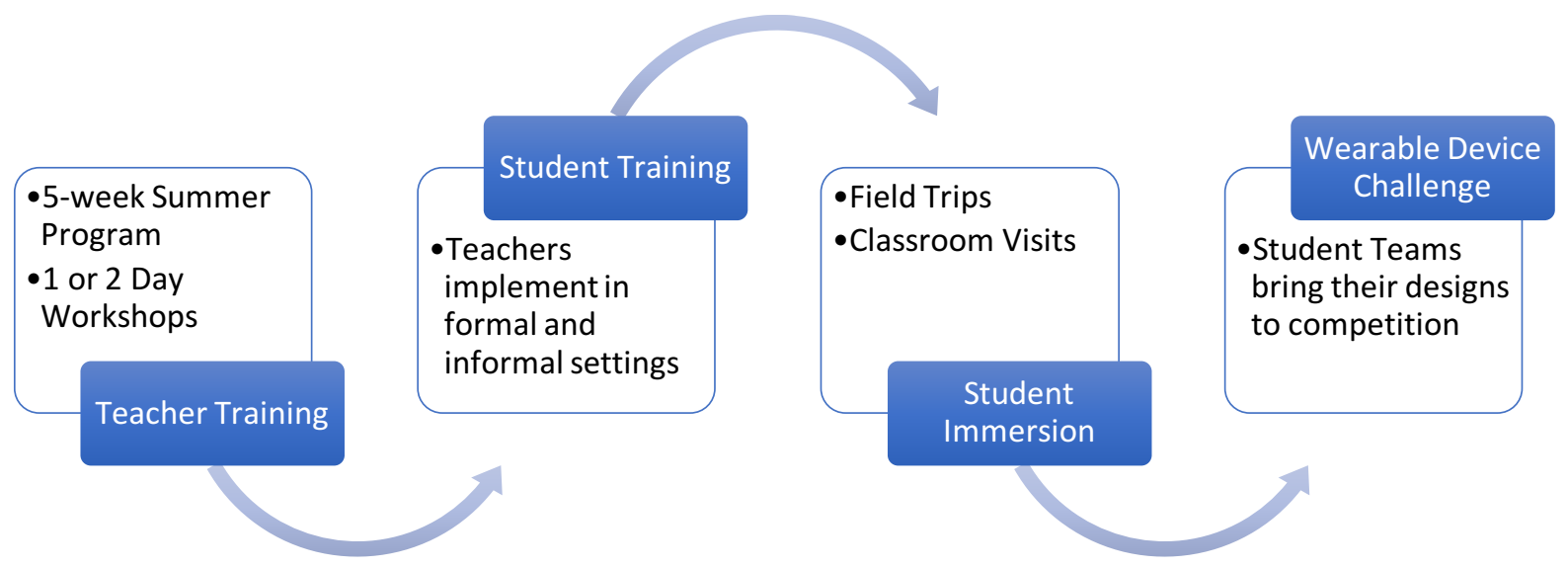

Figure 1: Program Structure

Throughout the program, participants (both teachers and students) learn a variety of essential skills while being exposed to the research and educational opportunities of the university. We broadly categorize these skills into three areas, which are described in more detail below: Engineering Design Thinking, Professional Skills, and Technical Skills.

\section{Engineering Design Thinking}

Encouraging active engagement in and excitement about engineering at a variety of grade levels from middle to high school is a key step in building the pipeline of students into STEM programs. Incorporating the EDP into secondary curriculum allows students to use project-based learning to develop a model or a prototype, giving them the critical opportunity to apply math and science content in real world engineering experiences ${ }^{3,4}$.

Over the past four years of developing this program with local teachers, we have found that one of the primary barriers to teachers implementing EDP and project-based, technology-rich programs in their classrooms is a lack of both self-efficacy and a support network to help them prepare and teach such lessons. Supporting conclusions can be found in the literature, particularly highlighting the pitfalls of teachers having only a superficial understanding of the $\mathrm{EDP}^{5}$. Working through an EDP with proper guidance gives teachers the tools and confidence to push their students outside of the comfort zone of concrete answers and encourages creativity and innovative thinking 5,6 .

For these reasons, every participant in this program is immediately immersed in the EDP so that they can become comfortable playing the role of an engineer. One of the foundational concepts of real-world Engineering is that there is not one right solution to a problem. Instead, it is a process and a way of thinking by which Engineers develop unique and creative solutions to problems. Very few teacher participants in the program have engineering backgrounds. Most have degrees in secondary education focused in science or math. We have even had physical education and fashion merchandising teachers in our program. We help teachers explore aspects of engineering design through an immersive project-based experience, but each must optimize their approach and methods for teaching EDP in their own classroom. 
We emphasize here that there are a variety of different EDP models in existence, and it is not necessary (or even beneficial) to impose one particular model ${ }^{5}$. As part of the process, teachers look at various models of the EDP to decide which will work best in their classroom. The model most teachers chose to use largely looked like the Massachusetts Department of Education Engineering Design Process Model $^{7}$ (Fig. 2). Some teachers preferred to further condense this model into easier acronyms such as D.E.A.L (determine the problem, evaluate possible solutions, apply the best solution, look back and reflect).

Teachers work through the EDP to design and build their own wearable device to address a One

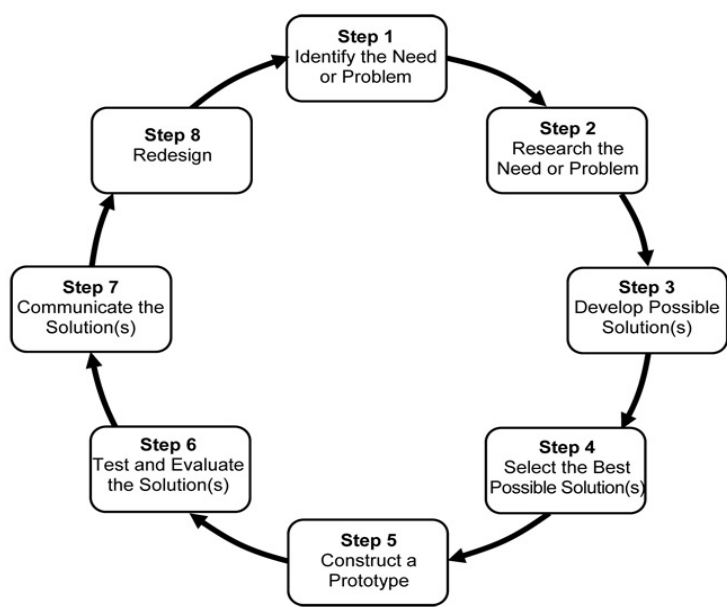

Figure 2: Massachusetts Department of Education Engineering Design Process Model (Massachusetts DOE 2006, p. 84) Health issue. With guidance from Center faculty experienced in teaching engineering design courses at the college level, participants are guided through key parts of the process in detail. For example, teachers learn about the process of ideation and practice using tools like concept mapping (Fig. 3). Teams also delve into the process of defining criteria and constraints for their projects. They go through a series of presentations and design reviews to defend their product design (Fig. 4). By the end of the 5 -week training, teachers feel confident using the EDP and have also developed their own tools and methods to guide their students in using the process in the classroom.

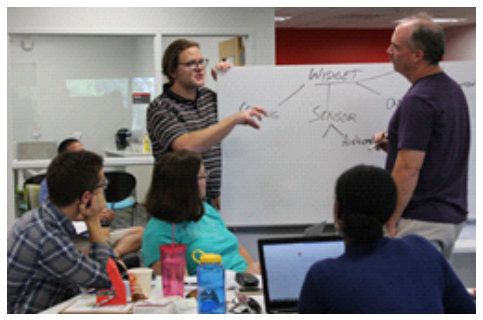

Figure 3: Teacher team engaging in guided ideation process

It is important to note here, that by virtue of our focus being on wearables and health, participants are also challenged to explore the broader implications of engineering design including: human factors, ethical considerations, issues related to privacy of information, etc. These are all critical aspects of real-world engineering challenges.

\section{Professional Skills}

The need for ongoing professional skills development of students, particularly in engineering, is prevalent. Perhaps most notably, the National Academy of Engineering publication, The Engineer of $2020^{8}$, outlines a number of desirable attributes among which we find: communication, creativity, and leadership. It is easy to find the consensus that technically-focused students often fail to

succeed, not due to technical incompetency, but rather a lack of creativity, teamwork, and communication skills ${ }^{9,10}$. Therefore, through the team-based WDC, we focus on teaching these key professional skills along with the technical STEM content.

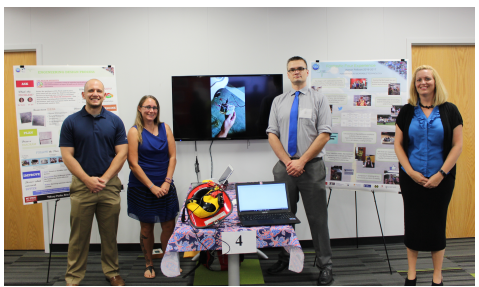

Figure 4: Teacher team presenting their design at the Summer Symposium. 
Successful completion of the project involves the active collaboration of all team members from the ideation phase all the way to the final prototype design. Throughout the exercise, participants work through the challenges of defining team roles and responsibilities, setting and meeting goals and deadlines, conflict resolution, etc. For many teachers, this environment is outside of their normal role as leader in the classroom. By being immersed in the student experience, they develop tools and methods for guiding their own students through the challenges, and ultimately highlighting the importance of collaborative work in engineering.

Oral and written communication skills are also targeted. In addition to designing and building a wearable device prototype, the challenge also includes requirements for an advertising campaign as well as a poster presentation. Teams must be able to articulate in both writing and in oral presentation the key aspects of their design in such a way as to convince the audience that their product is the best solution to an important and relevant problem.

\section{Technical Skills}

Throughout the program, participants also gain a wide range of technical knowledge and skills including: electronic circuits, programming, health and environmental sensors, human body energy harvesting, rapid prototyping tools, etc.

Participants are also exposed to the ongoing research on wearable devices and systems in the Center. Throughout the summer program, Center faculty and graduate students host lab tours, give presentations about their research, and engage teachers in hands-

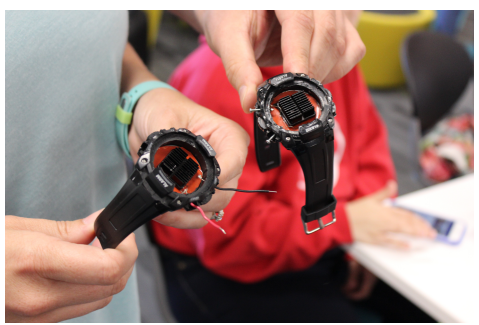

Figure 5: Teachers practice skills related to soldering and circuits by building and testing a thermoelectric harvesting watch.

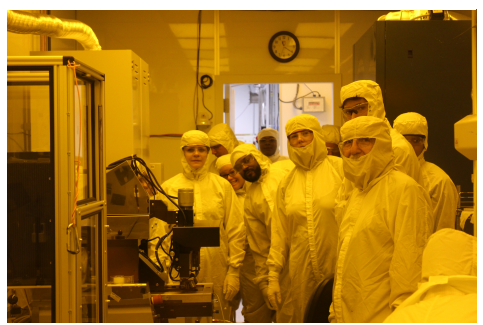

Figure 6: Teachers learn about Center research during a nanofabrication facility tour on projects and activities related to current research. A few examples include building and testing a thermoelectric harvesting watch (Fig. 5), motion capture for activity tracking, tours of the NC State Nanofabrication Facility (Fig. 6), Analytical Instrumentation Facility, and laboratories in the College of Textiles. During the school year, teachers can share these experiences with their students as well as organize field trips for students to visit these facilities and learn about current research.

\section{Implementation}

The program focuses on teachers and students at both the middle and high school level. It starts with the training of teachers through a 5-week intensive research experience in which teachers complete the design challenge while simultaneously developing lesson plans they will use to teach the material in their classrooms. Teachers implement the program in their schools and have students complete the challenge. Finalist teams from each school present their design at an annual competition. Throughout the process, representatives from the Center make classroom visits or host tours in order to support the teachers' implementation. To date over 50 teachers have completed the summer training. Over 400 students completed the project in 2016 and 16 
finalist teams competed in the 2016 WDC. Twenty-three teams participated in the 2017 Challenge, which took place on April 19th.

\section{Teacher Training}

Teachers from around the state of North Carolina were selected to participate in the five-week summer session through either the Kenan Fellows Program or as a R.E.T. (Research Experience for Teachers) for the Center. The Kenan Fellows Program for Curriculum and Leadership Development is a yearlong fellowship for K-12 teachers, which combines both professional development and an internship in a STEM field to allow teachers to encourage, engage, and promote STEM interests for their students ${ }^{11}$. The Kenan Fellows Program is funded through a partnership with NC State University. Teachers receive a $\$ 5,000$ stipend for the 5-week program (approximately 150 contact hours).

During the summer program teachers complete the WDC under the guidance of Center faculty and staff. The teachers also work with graduate students, faculty, and industry partners to explore fundamental principles of Center research in nanotechnology, energy harvesting, and sensors. In addition, teachers are required to create lesson plans that align with their curriculum and which they begin implementing with their students in the fall. The Center provides teachers with the appropriate technology and classroom resources they need to implement their lessons.

In order to expand the reach of this program, over the past year we have also developed an intensive 2-day workshop for teachers which provides the basic framework for teaching EDP and the Wearable Device Challenge. Together with the collection of online lesson plans created by our participants over the past summers and other online resources ${ }^{12}$, this workshop can give any teacher the basic framework needed to implement the program in their classroom. Our pilot implementation of the one-day workshop included 8 teachers and resulted in a new partnership with the Math/Science Education Network (MSEN) Saturday Academy program at NC State University. Teachers who participated in this workshop implemented the program in their classrooms and entered 4 teams in this year's competition.

\section{Student Training}

Teachers who have completed either the summer training or the condensed workshop go on to implement this new curriculum both in formal and informal settings. Some teachers find that the Challenge fits naturally into their existing curriculum, and implement it with an entire class or even an entire grade level. Other teachers find that after school clubs or other informal settings work better for their students. Regardless of the setting, the lessons learned, resources, materials, and support of the Center are available to them as their students work through the EDP to design and build their own wearable devices. We encourage teachers to close the loop by bringing students on field trips or having Center staff visit the classroom to further highlight the realworld relevance of the research that is currently happening within the university.

The comprehensive website ${ }^{12}$ available to students and teachers allows for student led learning, with the teacher serving acting as a facilitator for the project. This aspect makes the challenge 
ideal for not only project-based and problem-based learning, but also for implementation in both formal and informal educational settings.

\section{The Competition}

After teachers implement the units and lessons developed during the summer program, students will be strongly encouraged to enter in the WDC. The Challenge requires students to design a wearable device for a human, animal, or both, to address a "One Health" related issue. It is suggested that teachers introduce the students to the competition at the beginning of the spring semester, allowing them a full three months to complete their designs and compete in the state competition. The Challenge is geared towards both middle school and high school students, with the potential to eventually open the competition up to post-secondary students.

As part of Challenge, middle school students create a model of their wearable device, while high school students create a working prototype. Students may use either Arduino, or a similar platform as well as a variety of commercial off-the-shelf sensors to create their product. Teams are required to show evidence of working through an EDP starting with researching their chosen problem, coming up with realistic design criteria and constraints, ideation, prototyping, testing, re-design, etc. In addition to designing a prototype (high school) or model (middle school) students must create an advertising campaign for their product and a poster that documents their path through the EDP. Students present their products and posters in front of a panel of judges who score the projects based on a rubric.

Student teams consist of 4-6 members. If teachers have multiple teams, a preliminary judging is held at individual schools to determine the finalist teams that will compete in the Challenge. Due to current resource limitations, only 3 teams per teacher are allowed to enter the annual competition. Students and teachers can request various technology resources through our technology lending library. In addition, experts from the Center (industry personnel, faculty, and graduate students) will be available to answer questions students might have during the design process.

\section{Technology Integration and Accessibility}

The Center has developed suite of resources that provide accessibility of the resources necessary for the program, including

- a comprehensive website for both students and teachers to find resources, lesson plans, and information pertaining to the competition.

- an online lending library where teachers can check out various technology devices for their students to use during the WDC or if needed to teach one of the lesson plans. The library includes: various Arduino platforms, a 3D printer, TI Sensor Tags, Little Bits kits, fabric and sewing kits, soldering irons or various other materials necessary to create a wearable device.

- a demo library which consists of short 10-35 minute demonstrations that teachers and professors can use to teach topics of energy harvesting, wearable devices, computer programming, and the engineering design process. The demos in the library will not only 
have the demo planned out, but the materials need to complete the demo. These demos will be used as a hook to get students interested in the concepts being taught.

\section{Evaluation}

The evaluation plan consists of: (i) direct assessment of skills, (ii) self-assessments through preand post- surveys, and (iii) evaluation of programmatic factors. Teams completing the Challenge (teacher or student) are evaluated via a judging rubric at the culmination or the project. This rubric aims to assess technical competencies via demonstration of working prototype, familiarity with the engineering design process, oral and written communication skills. Teachers are also surveyed during the summer program and at the completion of the annual competition in order to gauge factors such as self-efficacy in teaching certain concepts, as well as feedback about their experience in the program to guide continuous improvement of our methods.

\section{Teacher Self-Assessments}

During the summer training program, teachers are asked to take pre and post evaluations to determine comprehension, growth, and self-efficacy in relation to wearable devices, energy harvesting, the engineering design process, and nanotechnology. Studies have shown that providing teachers with professional development though RET programs increases teachers' selfefficacy in their profession, provides teachers with ample resources outside of the classroom, and allows teachers to gain further mastery in their subject ${ }^{13,14}$. A summary of our findings is shown here. (Our survey instruments were adapted from the RET Network's pre-and post-surveys available on their website at: http://www.scienceteacherprogram.org/RETNetwork/)

When asked: "To what extent, if any, has the RET program stimulated me to think about ways I can improve my teaching?" All 100\% of respondents responded positively with either 'great extent' or 'moderate extent'. When asked: “As a professional development program for teachers, how would you rate the RET program in which you participated?" most teacher participants responded very favorably, with $89 \%$ rating it "very good" or "excellent for 2015 and $87 \%$ for 2014."

When asked about the relationship between participation in the RET program and student achievement, a teacher replied: "Yes, this experience will have an impact on student learning because I was exposed to many hands-on ideas that I can incorporate into my curriculum in order to improve understanding of certain topics as well as being provided different curriculum protocols that I can implement.” (RET Participant, July 2014)

Another participant describes the impact of being immersed in current research and having access to faculty and students as resources:

I feel that the exposure to current research and the interaction with the scientists was very beneficial. As teachers we are somewhat isolated in our classrooms and unaware of the research and development that is occurring in the university setting. I enjoyed being able to ask questions of the professors, graduate students and other faculty. I know that I will be able to take what I have learned back into my classroom. I will be able to use the knowledge I have gained from this experience to introduce my students to the STEM fields and to share my knowledge, pictures, and connections with my students. (RET Participant, July 2014) 
Our self-assessment results show that each year teacher efficacy has grown due to participation in the program (Table 1). We hope that this teacher growth will continue as our program grows and we continuously optimize our approach to meet the requirements of the teachers.

Table 1: RET Post-survey: Teacher efficacy/personal impact (longitudinal)

\begin{tabular}{|c|c|c|c|}
\hline Item & 2013 & 2014 & 2015 \\
\hline It increased my confidence in myself as a teacher & 3.30 & 3.26 & 3.39 \\
\hline It elevated my enthusiasm for teaching & 3.33 & 3.52 & 3.61 \\
\hline $\begin{array}{l}\text { It increased my interest in research and the ways that science, mathematics, or } \\
\text { technology can be applied }\end{array}$ & 3.70 & 3.78 & 3.78 \\
\hline It stimulated me to think about ways I can improve my teaching & 3.40 & 3.61 & 3.82 \\
\hline I believe I will be a more effective teacher & 3.40 & 3.57 & 3.78 \\
\hline It increased my interest and ability in networking with teachers and other professionals & 3.20 & 3.65 & 3.72 \\
\hline $\begin{array}{l}\text { It increased my motivation to seek out other experiential professional development } \\
\text { activities }\end{array}$ & 3.30 & 3.61 & 3.61 \\
\hline It increased my commitment to learning and seeking new ideas on my own & 3.20 & 3.50 & 3.67 \\
\hline
\end{tabular}

* 4 pt. Likert scale, with 1 being strong disagreement and 4 being strong agreement.

\section{Direct Assessment of Skills}

Both student and teacher teams are assessed via a judging rubric either at the end of the summer program (teachers) or during the competition (students). Table 2 shows the scoring rubric used in the first year of the competition. The rubric contains four primary categories: Problem Statement, Product Design, Advertising Campaign, and Poster. Each category is further broken down into several key areas of competency, each worth a maximum of 3 points.

Of the 16 student teams who competed in 2016, the average rubric score was a 30.4 out of 39 points, with students scoring highest in the "Problem Statement" category (average 2.6 out of 3) and lowest in the "Advertising Campaign" category (average 2.0 out of 3 ). There was almost no discrepancy between the middle school and high school scores (averages of 30.3 and 30.5 respectively).

Table 2: Initial Judging Rubric for WDC

\begin{tabular}{|l|l|l|l|}
\hline 3 Points: Exemplary Work & 2 Points: Good/Average Work & 1 Point: Below Average Work & 0 Points: Category missing \\
\hline
\end{tabular}

\begin{tabular}{|c|c|c|}
\hline Category & Description & Score \\
\hline \multicolumn{3}{|c|}{ Problem Statement } \\
\hline $\begin{array}{l}\text { Problem } \\
\text { Selection }\end{array}$ & The problem selected is: Relevant to today's healthcare concerns; Measureable; Related to One Health & \\
\hline $\begin{array}{l}\text { Solution } \\
\text { Research }\end{array}$ & $\begin{array}{l}\text { The solution: Addresses the problem that the group selected; Is designed for a targeted audience; Is well } \\
\text { researched and students can defend their design solution }\end{array}$ & \\
\hline \multicolumn{3}{|c|}{ Product Design } \\
\hline Feasibility & $\begin{array}{l}\text { The product design: Works well in the chosen environment; Has chosen appropriate sensors for a } \\
\text { wearable device, Manages data in a manner conducive to the technological needs, existing } \\
\text { infrastructure, and surroundings; Functions as intended } * * * \text { High school only }\end{array}$ & \\
\hline Wearability & $\begin{array}{l}\text { The product is able to: Withstand appropriate environmental parameters (i.e. motion, temperature, } \\
\text { humidity etc.); Is constructed of a material that is biocompatible; Is generally comfortable and not too } \\
\text { bulky to wear }\end{array}$ & \\
\hline Aesthetics & $\begin{array}{l}\text { The product designed considers: Cultural sensitivity of the area in which the design will be distributed; } \\
\text { Aesthetics and visual appeal; The target demographic OR is neutral (e.g. bright colors for children, }\end{array}$ & \\
\hline
\end{tabular}




\begin{tabular}{|l|l|l|}
\hline \multicolumn{2}{|l|}{$\begin{array}{l}\text { Sensor } \\
\text { placement }\end{array}$} & $\begin{array}{l}\text { Thiversal sizes, etc.) } \\
\text { That maximize comfort and minimize discomfort for the wearer; That are non-invasive unless } \\
\text { absolutely necessary. }\end{array}$ \\
\hline Power & $\begin{array}{l}\text { The power source is: Appropriate for a wearable device; Easily accessible in the selected location or } \\
\text { desired market; Long-lasting and/or a self-powered platform has been considered }\end{array}$ \\
\hline \multicolumn{5}{|c|}{ Advertising Campaign } \\
\hline Instructions & $\begin{array}{l}\text { The advertising campaign contains instructions that: Concisely explain how to use the device; Use } \\
\text { appropriate language for the targeted audiences; Use appropriate and informative graphics and designs }\end{array}$ & $\begin{array}{l}\text { The advertising campaign contains: Specific information about how the product will help prevent or } \\
\text { monitor the chosen health issue; Information from reputable sources; A call to action that empowers the } \\
\text { user in social responsibility and educating others }\end{array}$ \\
\hline Awareness & $\begin{array}{l}\text { The advertising campaign: Is appropriate to reach the target audience/user; Includes advertising that is } \\
\text { ecologically friendly and explains how the product is ecologically friendly; Addresses sustainability } \\
\text { (e.g. longevity, training in the community) once the initial advertising campaign is complete }\end{array}$ & \multicolumn{1}{|c|}{ Poster } \\
\hline Feasibility \\
\hline Instructions & $\begin{array}{l}\text { The poster contains instructions that are: Concise on how to use the device; Use appropriate language } \\
\text { for the targeted audiences; Use appropriate and informative graphics and designs }\end{array}$ & $\begin{array}{l}\text { The poster explains: Who the target population is (who is affected by this health issue; What percentage } \\
\text { of this population will be helped by the design; How prevalent this issue is nationally, globally, etc.; } \\
\text { The need for the device }\end{array}$ \\
\hline $\begin{array}{l}\text { Target } \\
\text { Population }\end{array}$ & $\begin{array}{l}\text { The poster explains: How this health issue relates to One Health; How the device is powered and why } \\
\text { this type was chosen; How to use the device and the lifespan of the device }\end{array}$ \\
\hline Background \\
Information
\end{tabular}

Based on feedback received from teachers and judges as well as our internal assessment of the judging rubric, this rubric was updated for the upcoming year's competition. Specifically, we found that the rubric did not directly target our three key skill sets: Engineering Design Thinking, Technical Skills, and Professional Skills.

Insufficient emphasis was placed in the judging process on assessing the students' understanding of the Engineering Design Process itself. While the "problem statement" was judged, as was the "product design", students were not expected to explicitly describe their understanding of the EDP. To this end, an EDP category was added to the judging rubric to explicitly score the student's understanding and application of this process.

We also added a presentation category to explicitly focus on all team members' ability for oral communication in addition to the written information provided. In addition, we saw a need to highlight the technical skills of those middle school teams who did have working prototypes with a bonus point in the scoring rubric. Finally, the importance of a real-world connection is highlighted through the addition of a "relevance to one health" category. This ensures that teams are researching and aiming to address relevant issues related to global health.

The updated scoring rubric is shown in Table 3. This rubric was piloted with our summer 2016 teacher cohort. Among the five teacher teams, the average score was 35.8 out of 42 points, with scores ranging from 32.3 to 37.6. More critically, we found that, on average, teams performed equally well in all of the judging rubric categories. This new rubric will be implemented with student participants at the 2017 annual competition.

Table 3: Updated Judging Rubric for WDC 


\begin{tabular}{|c|c|c|}
\hline Category & Description & Score \\
\hline \multicolumn{3}{|c|}{ Engineering Design Process } \\
\hline EDP & Selected, identified, and explained an engineering design process on their poster. & \\
\hline Poster & Evidence of following an engineering design process. & \\
\hline \multicolumn{3}{|c|}{ Prototype Design } \\
\hline Aesthetics and Wearability & $\begin{array}{l}\text { The design considers comfort, culturally sensitive designs, visually appeal, and } \\
\text { durability. }\end{array}$ & \\
\hline $\begin{array}{l}\text { Sensor selection and } \\
\text { placement }\end{array}$ & The sensors are appropriately selected and placed for the intended use of the device. & \\
\hline Feasibility & $\begin{array}{l}\text { Device works in selected environment and appropriately transmits data for intended } \\
\text { target population. }\end{array}$ & \\
\hline $\begin{array}{l}\text { Sustainability/ } \\
\text { Power }\end{array}$ & $\begin{array}{l}\text { Explanation of future iterations of design uses self-powered energy harvesting (current } \\
\text { design does not need to be self-powered). }\end{array}$ & \\
\hline Functionality & The device functions as intended. (This Category is for High School only). & \\
\hline Middle School Bonus & $\begin{array}{l}+2 \text { - Device functions properly as intended } \\
+1 \text { - Device works some of the time as intended }\end{array}$ & \\
\hline \multicolumn{3}{|c|}{ Advertising Campaign } \\
\hline Why /Who & $\begin{array}{l}\text { The advertising campaign provides information on why the device is needed and who } \\
\text { will benefit from its use. }\end{array}$ & \\
\hline What/How & The advertising campaign explains how to use the device and what the device does. & \\
\hline \multicolumn{3}{|c|}{ Relevance to One Health Initiative } \\
\hline Explanation & All group members can articulate the goals of the One Health Concept. & \\
\hline Connection & The device is a solution for a One Health topic. & \\
\hline \multicolumn{3}{|c|}{ Presentation } \\
\hline Ad Campaign and Poster & The poster and ad campaign are visually appealing, cohesive, and concise. & \\
\hline Verbal Communication & $\begin{array}{l}\text { All students in the group actively participate and any student can articulate any concept } \\
\text { related to their project. }\end{array}$ & \\
\hline
\end{tabular}

\section{Conclusion}

The Wearable Device Challenge is rooted in the research and innovation ecosystem of the Center and its vision: to have a transformational impact on the way doctors and patients manage wellness through wearable, self-powered health and environmental monitoring systems. At its core, the program teaches middle and high school teachers and students how to apply the Engineering Design Process to solve real world problems through a project based approach. Through these projects participants learn a variety of essential technical and professional skills while being exposed to the research and educational opportunities of the university. Among these are: engineering design process, electronic circuits, computer programming, sensors, energy harvesting, prototyping, human factors in engineering design, communication, and teamwork.

So far, the program has engaged over 50 teachers and several hundred students in North Carolina through real world, relevant, hands-on engineering design challenges. Through the program, teachers are empowered to introduce Engineering Design into a variety of both formal and informal educational settings, and students are given the opportunity to explore exciting, cuttingedge applications of science and technology that will inspire them to continue in STEM fields.

Ongoing work aims to expand access to the competition state-wide through additional teacher workshops and online resources that give teachers access to the tools and training needed to implement the challenge more broadly. 


\section{References}

[1] The Center for Advanced Self-Powered Systems of Integrated Sensors and Technologies. (2012). Retrieved from https://assist.ncsu.edu.

[2] One Health Initiative. One Health Initiative will unite human and veterinary medicine. Retrieved from http://www.onehealthinitiative.com/

[3] Berland, L., Steingut, R., \& Ko, P. (2014). High School Student Perceptions of the Utility of the Engineering Design Process: Creating Opportunities to Engage in Engineering Practices and Apply Math and Science Content. Journal of Science Education and Technology, 23(6), 705-720.

[4] Dym, C. L., \& Little, P. Engineering Design: A Project-Based Introduction. 2004, Hoboken.

[5] Hynes, M. M. (2010). Middle-school teachers' understanding and teaching of the engineering design process: A look at subject matter and pedagogical content knowledge. International Journal of Technology and Design Education, 22(3), 345-360.

[6] Fan, S., \& Yu, K. (2015). How an integrative STEM curriculum can benefit students in engineering design practices. International Journal of Technology and Design Education.

[7] Massachusetts DOE. (2006). Massachusetts science and technology/engineering curriculum framework. Massachusetts.

[8] National Research Council. (2004). The Engineer of 2020: Visions of Engineering in the New Century. Washington, DC: The National Academies Press.

[9] Stephens R. (2013). Aligning Enigneering Education and Experience to Meet the Needs of Industry and Society. The Bridge, 43(2).

[10] Nair C, Patil A, Mertova P. (2009). Re-engineering graduate skills-a case study. European Journal of Engineering, 34(2), 231-139.

[11] Kenan Fellows. (2016) About Us. Retrieved from https://kenanfellows.org/about-us/

[12] ASSIST Wearable Device Challenge. (2016). Retrieved from https://assist.ncsu.edu/wearable-device/

[13] Pop, M. M., Dixon, P., \& Grove, C. M. (2010). Research Experiences for Teachers (RET): Motivation, Expectations, and Changes to Teaching Practices due to Professional Program Involvement. Journal of Science Teacher Education, 21(2), 127-147.

[14] Yavuz, S. (2013). Who are the Science Teachers that Seek Professional Development in Research Experience for Teachers (RET's)? Implications for Teacher Professional Development. Journal of Science Education and Technology, 22(6), 934-951. 